\title{
Media Concentration and Journalistic Independence in Pakistan Audience and Journalists' Perspectives
}

\author{
Muhammad Riaz Raza ${ }^{1^{*}}$ \\ (iD) 0000-0002-6993-9003
}

\section{Muhammad Usman Saeed ${ }^{2}$}

(D) 0000-0002-9125-7527

\section{Zafar Ali ${ }^{3}$}

(iD) 0000-0002-7884-9763

${ }^{1}$ Assistant Professor, Media Studies, Bahria University, Islamabad, PAKISTAN

${ }^{2}$ Assistant Professor, Media and Communication, University of Management \& Technology, Sialkot Campus, PAKISTAN

${ }^{3}$ PhD Scholar Communication \& Media Studies, University of Punjab Lahore, PAKISTAN

*Corresponding author: mriaz.buic@bahria.edu.pk

Citation: Raza, M. R., Saeed, M. U., \& Ali, Z. (2022). Media Concentration and Journalistic Independence in Pakistan Audience and Journalists' Perspectives. Online Journal of Communication and Media Technologies, 12(1), e202205. https://doi.org/10.30935/ojcmt/11462

\section{ARTICLE INFO}

Received: 31 Jul 2021

Accepted: 11 Nov 2021

\section{ABSTRACT}

Media concentration has often been mechanized to weaken the culture of media competition and journalistic independence to safeguard media's commercial and ideological interests. Herman and Chomsky's (1988) propaganda model is utilized to measure the content creation, dissemination and consumption in terms of hegemony of media and public trust. Two questionnaires have been developed to get the responses on media ownership, media and content concentration, journalistic independence, and public trust in media from journalists and media consumers. Results of the study and ownership patterns and practices show that Pakistani media platforms; print, electronic and social are highly concentrated in terms of ownership and audience share. The majority $70 \%$ of the audiences have shown low confidence in the media. Regarding the influence of cross-media ownership on content diversity, the majority $64 \%$ of audiences viewed that cross-media ownership has a significant negative impact on content diversity and journalistic independence across the mediums. $60 \%$ of the journalists do not feel free to express their personal opinion on any issue if it differs from official line of the outlets. Majority $75 \%$ journalists feel influence from the political and religious groups on the overall journalistic independence and $61 \%$ of audiences have the opinion that media do involve in partisanship on political, religious, ethnic, and ideological grounds. $38 \%$ of journalists say that media associations do not support them at the time of pressure on them while $35 \%$ observed that the associations do helpful to some extent. A perfect correlation of $>.92$ between journalists and audience opinion on content concentration has been observed. Audiences are considered TV medium as the most trusted media platform with a $48 \%$ score while social media is remained at second place having a score of $26 \%$.

Keywords: media concentration, journalistic independence, audience perspective, journalists perspective, content diversity

\section{INTRODUCTION AND LITERATURE REVIEW}

The media is often seen as a tool of a political movement aimed at gaining the support and opposition of influential political elites. Journalist and news critic Liebling et al. (2006) says that press freedom belongs to those who own press freedom cynical comments make the property a central issue in modern media research. This can also explain why politicians often tend to access the media, that is, to promote their political ideology among voters. "Media ownership depends on the particularities of the media systems in which

Copyright (c) 2022 by authors; licensee OJCMT. This article is an open access article distributed under the terms and conditions of the Creative Commons Attribution License (http://creativecommons.org/licenses/by/4.0/). 
ownership evolves whereas concentration is a general trend in countries where private media ownership is a dominant form the impact of ownership on news and journalism depends on how the relationship between media, state, and other industries has developed" (Sjøvaag \& Ohlsson (2019).

Alger (1998) believes that today's media plays a key role in democratic operations, and entertainment and other functions and programs in the media have a powerful influence on society as a whole. In particular, sharing basic ideas and images is essential to determine whether the democratic process is proceeding as expected, is shaking or undermining. Light (2017) says that "media consolidation is the concentration of ownership of our news sources into the hands of fewer and fewer corporations." Media ownership has emerged as an increasing number of concentrated, ruled with the support of some key players in a social, political system. Shoemaker and Reese (1996) write that "hegemony is a broad theoretical approach suggesting that media content is influenced by the ideology of those in power in society" (p. 7). Being key parts of the economic system that are controlled by those with economic power. "In 1983, 90\% of the US media was controlled by 50 companies; as of 2011, $90 \%$ was controlled by just 6 companies" (Corcoran, 2016). Murdoch, the CEO of News Corporation is considered as one of the most powerful in the club of media tycoons. Murdoch's hegemony is very genuine proof that elite news media get power to control, act and behave in a manipulated way from countless media organizations in a concentrated fashion. Paveli (2010) says that Prime Minister of Italy Silvio Berlusconi is widely known as a media conglomerate who has 3 big television stations and even there are 3 public stations in Italy. His media empire is controlling 3 personal stations in the country. Doyle (2002) says that "Berlusconi's media empire has unceasingly emerged as a target of public opprobrium for its capability to sway political gimmickry in Italy in approaches that weaken the general public sphere and the life of a plural democracy."

The research study of Media Ownership Monitor Pakistan (MoMP, 2019) on Indian media ownership shows, "that the country's print media market is highly concentrated. Four outlets - Dainik Jagran, Hindustan, Amar Ujala, and Dainik Bhaskar - capture $76.45 \%$ of readership share within the national Hindi language market." The research further explored that majority of leading media organizations are running by conglomerates. Interestingly these media companies are still under the control of founding families who have businesses in other fields. Some of these families have had political ties for many decades. According to the Centre for International Media Assistance (CIMA, 2021), clear information about media ownership in Bangladesh is not possible due to the non-availability of credible and reliable data publicly. It is difficult to know who runs their Media Board of Directors due to a lack of transparency in the media business. The media organizations do not publish their financial reports and the data is not available for any scrutiny or audit.

Riaz and Rehman (2021) explored that "there are three key overlapping features dominate the media ownership landscape of Bangladesh. First, many outlets are controlled by family members. Second, most owners of media outlets are directly or indirectly affiliated with political parties. And finally, almost all the media outlets are owned by big business groups with diverse financial interests." The report further sheds light on the issue of freedom of the press in the country by exploring that "The 2020 annual report of the Reporters without Borders (2020) writes, "Bangladeshi journalists have been among the leading collateral victims of the tougher methods adopted by the ruling Awami League and its leader, Sheikh Hasina, the country's prime minister since 2009." From the lines above, one can understand that expanding concentrated media landscape has been one of the major variables in the way of freedom of the press and democracy. Baker (2007) says that concentrated media make the ground for a person to exercise enormous power in unequal and undemocratic wishes. Sjøvaag and Ohlsson (2019) cited Hardy (2014) that the scholarship of political-economic came in the 1960s which clarifies how the media ownership influence and control the media organization and its labour.

Most of the African countries lived up under military, hybrid and autocratic regimes over the past many decades, however, the expansion of media independence and liberalization policies have played a key role in democratization (CIMA, 2019). There was a single state-owned television station three decades ago in Senegal, there was just one, government-controlled television station. The situation was changed altogether with the permission to own a channel in the private sector and independent broadcasters back in 1992. Within 25 years the media landscape in the country had changed altogether as there were around 300 radio stations in Senegal, apart from countless television, print, and digital platforms (CIMA, 2019). This study further says that, "news media concentration in Pakistan in terms of both ownership and audience share is very high. The top 
4 television channels, radio stations, newspapers, and news websites in each category have over $50 \%$ of the country's entire audience share for each category."

"The cross-media ownership concentration in Pakistan is $60 \%$ of the accumulative audience shares of top seven media groups owning media in more than one of four media categories. There are seven cross-media owners in Pakistan's sample of top 40 media groups with the highest audience shares, including Jang Group, Express Group, Government Group, Nawa-i-Waqt Group, Samaa Group, Dawn Group, and Dunya Group - between them they constitute $60 \%$ of cross-media audiences shares of top 40 media outlets in terms of audience share in the country (MoMP, 2019). The government is among the top three cross-media owners (PTV and PBC + FM stations) in the country. According to the Reporters without Borders (2019) that audience shares of top 40 media outlets (top 10 each in TV, radio, newspapers, and online), there are only seven media groups in Pakistan that own media entities in more than one media category. TV media and online media are the mostowned media (5 of 7 media groups) in the cross-media mix of four categories and radio is the least-owned media ( 2 of 7 media groups). Pakistan's media market has experienced massive growth commensurate with an expansion in the media landscape, economic growth, and increasing audiences in the past decade overall. However, recent political transition and stumbling economy has affected the media market and disrupted funding-related control, and is changing it to other means of influence including regulatory coercion and censorship. Cross-media ownership in Pakistan is restricting content diversity and promoting audience concentration. Regarding economic dynamics of media business as a report of Fùrnemont and Trpevska (2020) "the marginal costs can be very low, the cost of an additional reader of a newspaper is just the material cost of the paper, while an additional viewer of a TV or radio show has no additional costs)."

Rasul and Proffitt (2013) quoted in a study that "PEMRA (Pakistan Electronic Media Regulatory Authority) accelerated the growth of electronic media in Pakistan, it failed to promote local and diverse media as PEMRA policies supported diagonal integration and lead to concentration of ownership (PEMRA, 2007)."

The present study focuses on media ownership trends, media freedom, and how these two variables could have affected the public trust in media in Pakistan.

\section{Media Market and Media Ownership Trends in Pakistan}

It is evident from Table 1 that cross-media ownership concentration is $69 \%$ which comes under the highrisk indicator of media concentration parameters. These 8 media groups having 69\% of cross-media productions in the country.

Table 1. Cross-media ownership concentration in Pakistan

\begin{tabular}{lc}
\hline Media group & Audience share \\
\hline Jang Group & $27 \%$ \\
The Government & $10.22 \%$ \\
ARY Group & $10.06 \%$ \\
Express Group & $8.28 \%$ \\
Samaa Group & 5.92 \\
Dunya Group & $2.83 \%$ \\
Nawaiwaqt Group & $2.32 \%$ \\
Dawn Group & $1.79 \%$ \\
\hline
\end{tabular}

Source: MoMP (2019). Total 68.83\%

Jang Group is leading with a $25 \%$ television audience share among the top four media groups as listed in Table 2. ARY News and state-owned PTV News have an almost equal share (12\%) of the television audience. Reporter without Borders in their report of 2017, explored few facts about media concentration in Pakistan including newspapers, radio, and television, and internet media according to MoMP (2019) the audience share of top 10 TV news channels in the country with most-watched Geo News 25\% to least-watched Dunya News with audience share 3\%. They further discovered some evidence in Table 2 about media concentration in terms of readership share in top 10 newspapers, leading widely read Daily Jang with $21 \%$. In this way, Jang and Geo Group is the largest media group in the country which has cross-media ownership with half a dozen channels, 3 big newspapers, a series of magazines, and internet journalism as well. According to the report of MoMP (2019), Table 3 shows the top ten newspapers in terms of audience share. 
Table 2. Television audience concentration in Pakistan

\begin{tabular}{lcc}
\hline Media group & Outlet & Audience share \\
\hline Jang Group & Geo News & $24.50 \%$ \\
ARY Group & ARY News & $12.27 \%$ \\
The Government & PTV News & $11.24 \%$ \\
Samaa Group & Samaa TV & $6.99 \%$ \\
\hline
\end{tabular}

Source: MoMP (2019). Total 54.99\%

Table 3. Readership share of top-ten print newspapers

\begin{tabular}{lc}
\hline Newspaper & Readership share \\
\hline Daily Jang & $21.30 \%$ \\
Daily Express & $17.05 \%$ \\
Daily Nawa-i-Waqt & $13.06 \%$ \\
Daily Khabrain & $11.08 \%$ \\
Daily Kawish & $5.36 \%$ \\
Daily Dawn & $2.82 \%$ \\
Daily Mashriq & $2.82 \%$ \\
Daily Koshish & $1.71 \%$ \\
Daily Ummat & $1.68 \%$ \\
Daily Jasarat & $1.00 \%$ \\
\hline
\end{tabular}

Source: MoMP (2019). Total 77.88\%

\section{Online Media Concentration}

Pakistan has been able to affect a growth-oriented, lively digitized society with web and online media expansion in numbers and scale in this media competitor market. Web platforms on this planet are allowing netizens to express themselves excitedly. Less complex, speedier, and cheaper web get to be fuelling social media utilize and supporting a burgeoning online current endeavors media and community information stages that are driving a national conversation from a people's point of seeing. People are getting more options in having news and other required information, comparatively, at a cheaper cost in recent years. Due to media and content concentration on the sources of information, people are getting away from traditional media information systems in search of diversity in media content. Top 4 native online news websites command over half of all online media audiences (MoMP, 2019).

There is a similar concentration trend in online media outlets as visible in Table 4. Dawn, Jang, Nawa-iWaqt, and Express groups are dominating in this field as well. They have $27 \%$ of the audience share as far as the online users are concerned. As for as the radio landscape in Pakistan is concerned "a total of 62 radio channels of the state-owned Pakistan Broadcasting Corporation today cover $98 \%$ of the population and $80 \%$ of the total area in Pakistan. These include $40 \mathrm{FM}$ and $22 \mathrm{AM}$ stations. The AM channels include five current affairs channels" (Media Landscape (2017). There is no exception to this medium in terms of media concentration, however, the state remains at the top in the information delivery through radio waves.

Table 4. Audience share of top-ten news websites

\begin{tabular}{lc}
\hline News websites & Audience share \\
\hline Dawn.com & $4.56 \%$ \\
Jang.com & $4.22 \%$ \\
Thenews.com.pk & $3.15 \%$ \\
Express. Pk & $2.72 \%$ \\
Express.com.pk & $2.72 \%$ \\
Tribune.com.pk & 2.59 \\
Geo. tv & $2.47 \%$ \\
Dailypakistan.com.pk & $2.01 \%$ \\
Dunya news. Tv & $1.39 \%$ \\
Nawaiwaqt.com.pk & $0.29 \%$ \\
\hline
\end{tabular}

Source: MoMP (2019). Total 26.52\% 


\section{Public Confidence in Media}

Fischer (2019) opines that the issue of trust and belief in news media is a talk of the town in the 'informed globe'. Different studies in situations, tell us that the issue of trust in the media is declining with every passing day. Several examples of unhealthy and unprofessional approaches can be quoted to verify such practices like in the UK, US, and other parts of the world. This includes partisanship and fake news genres. Many scholars call it a serious crisis in a democratic country. US media is considered a home of media conglomerates is also under criticism for its fake, bias and partisan coverage. Different surveys show that majority of Americans do not believe their national media. World Economic Forum 2017 report tells "traditional media's trust among the public is touching its bottom even throughout the world. Further, it reports that people prefer to interact interpersonally or on the internet to discuss matters. However, few questions arise like whether they are more qualified and media literate to understand the media manipulations, biases, polarization, and tilting or commercialization? This is not only a matter of US media and the public while in every country having established and matured media.

US media, to a larger extent, has been used for the dehumanization of the Iraqi forces while humanization of their army during the Iraq-US war in 1991 and invasion of Iraq in 2003. The practice of embedded journalism was a part and parcel even during the war-on-terror in Afghanistan. Mainstream media like CNN and other national media was remained hand in hand in producing hundreds of footage with great achievement. It was only due to the enormous pressure of the public which was divided on many of these untargeted and blind wars. To legitimate, their war crimes, US forces were desperate to get and restored their confidence among the public, and to happen this they need embedded journalism. According to Papendrea and Tiffen (2016), "61\% of Australians believed that the Government should restrict the concentration of media ownership in Australia." According to Gallup (2020), public confidence in the media has been in decline in America in recent decades. The survey says the public confidence was $46 \%$ in 1993 which has been dropped to $18 \%$ in 2020.

A survey was conducted to measure public trust in media by European Broadcasting Union (2017). According to this survey, UK print media especially newspapers were considered as the least trusted media platforms in Europe. According to the results, Germany, Spain, and Slovenia remained in the top three among 33 countries on the inquiry regarding public trust in newspapers. However, the majority of UK citizens were more satisfied and believed social media as the most trustworthy media platform. According to Newman et al. (2020) "as of April 2020, trust in the media's coverage of COVID-19 was relatively high in all countries, at a similar level to national governments and significantly higher than for individual politicians. Media trust was more than twice the level for social networks, video platforms, or messaging services when it came to information about COVID-19." However, the context of this report is about general awareness regarding the virus and it has been remained prominent among all the media in terms of a pandemic and its global impact.

Jesper and Michael (2011) were of the view that changes in media situations over the last few decades may have expanded audiences' impact over media content, but it may further have expanded the impact of other clusters such as advertisers and media owners. They argued that there are conflicting trends about the impact of journalists and source organizations. While in other cases, it shows up conceivable to anticipate expanding influence. The role of the editor has been expanding manifolds as a decision-maker for content selection to safeguard the interest of the media outlet even, sometimes, on the cost of objectivity and truth. Shoemaker and Reese (1996) quoted Mills (1956) that "the converging benefits of business, economic, and military elites from an apex at the top of the social structure" ( $p$ 223).

\section{Problem Statement}

This study addresses that, despite Pakistan has made great strides in understanding freedom of press and speech in the media business, ownership concentration, content concentration, homogenous content, and public trust have often been mechanized to weaken journalistic independence, content diversity, media pluralism and competitive media environment.

\section{Objectives}

$\checkmark$ To measure journalists' perceptions regarding the influence of media ownership in media practices. 
$\checkmark$ To measure the public's perception of media independence and public confidence in media.

$\checkmark$ To know the most and the least trusted media platform.

$\checkmark$ To highlight the patterns of media concentration in Pakistan.

$\checkmark$ To highlight the practices of the content concentration in Pakistan.

$\checkmark$ To explore partisanship of the media on different political, social and religious issues.

\section{Hypotheses}

H1. Media concentration will affect the editorial independence of journalists.

H2. Cross-media ownership will affect the diversity of news content.

H3. There will be a relationship between public confidence in media and public perception about owners' influence.

H4. The TV will be the most trusted news platform.

H5. Social media will be the least trusted platform.

H6. Media concentration will lead to content concentration.

H7. Journalists will not be free to voice their opinion if differs from the official line.

\section{METHODOLOGY}

\section{Conceptual Framework}

This study adopted Chomsky and Herman's (2002) propaganda mode as a major theoretical line while the media ownership theory proposed by Shoemaker and Reese (1991) has also been utilized. This follows the way by which capital and power chemistry have the capacity and ability to restrict and mend opinion and viewpoint diversity and news stuff that may be best safeguard tools to the interests of the private media owners. In the study of media, it looks impossible to isolate ownership for being an independent variable. It has some logical ground that it is seen in social, political, and economic conditions where media ownership exists. Chomsky and Herman's (2002) propaganda model states that news is manufactured keeping in view the hegemonic desires of the elite. Chomsky (2004) further opined that "mass media have defined the role of mass propagandists rather than functioning as the fourth estate. It is quite right to say that present day's media is operating as more than a mouthpiece and the corporate elite. "News organizations financed primarily by "interest" sources are far less likely to place great emphasis on impartiality and newsworthiness" (Shoemaker, 1987). Harkinson (2014) observed that "one in four local news channels do not produce news content."

A propaganda model focuses on this inequality of wealth and power and its multilevel effects on massmedia interests and choices. In countries where the levers of power are in the hands of a state bureaucracy, the monopolistic control over the media, often supplemented by official censorship, makes it clear that the media serve the ends of a dominant elite. It is much more difficult to see a propaganda system at work where the media are private and formal censorship is absent (Herman \& Chomsky, 1988).

They further argued that control groups of the media giants are also brought into close relationships with the mainstream of the corporate community through boards of directors and social links. This hypothesis states how the layers of propaganda model manipulate the consent of the people by using different tools in the mass media. Their model suggests how the media economy is penetrated to control media content and populace and how the social, political, economic, and information attitudes are fashioned to get their desired objectives through propaganda techniques. Since political and media globalization is at its full bloom due to the sophistication in telecom, transport, and information fields, the impact, and utility of their propaganda model are valid all over the world (Herman \& Chomsky, 1988). Ownership of news media takes many forms: state ownership, family ownership, party ownership, trust ownership, public or corporate ownership. The main concern with ownership in journalism scholarship is market concentration and monopolization, and the undue effects this may have on media diversity, public opinion formation, democracy, and journalistic autonomy. Further, it is understandable that the "middle-class position of the journalistic profession is a 
guarantee of their subservience to the capitalist system" (Gans, 1979). In this regard, journalists see and interpret the world through similar lenses, in much the same way as the real holders of power.

Parenti (2016) says that "we hear about political repression perpetrated by officially designated "rogue" governments, but information about the brutal murder and torture practiced by U.S.-sponsored surrogate forces in the Third World, and other crimes committed by the U.S. national security. The state is denied a public airing." It is called suppression by omission and it is being practiced in all media of the world. The interface between ownership concentration and commercialization of news coverage as a product is therefore tied to the benefit motive. The interface between proprietorship control and journalism's independence is tied to political and economic interface (Sjøvaag \& Ohlsson, 2019).

On the method of evaluation of the media concentration and diversity in content; Council of Europe (2009) says that "existing monitoring exercises show that both qualitative and quantitative information is used for the evaluation of indicators, with the majority of information coming from qualitative i.e. opinions, judgments, etc." However, both the methods are exercised in the media markets. The report further explored that "keeping in view the complexity of the issue and many variables that influence the media diversity (size of the market, size of the audience, media culture, etc. (Council of Europe, 2009). Since no regulatory body in Pakistan is constituted and responsible to monitor content concentration and diversity and media pluralism; the role of media owners and journalists becomes the centre of the debate. Further, media associations are more or less considered as the mouthpieces of these media-business tycoons.

"There is a sharp decline of up to $50 \%$ in federal and provincial governments' advertising, while private sector advertisements have declined between $30 \%$ and $40 \%$, forcing media owners to unwillingly lay off workers" (Arab News, 2019). The number of journalists in Pakistan is estimated at around 10,000 in 2010, however, with the shrinking of traditional media landscapes, about 3,105 journalists have lost their jobs in 2019, (Karachi Union of Journalists, 2019) and the process of this sharp layoff is going on and since 2018 many journalists lost their jobs. There is no exact data available or information maintained by journalist associations about the total strength of journalists in Pakistan. Keeping in view, the continuous layoffs trend in the Pakistani media landscape, the working journalists who were based in twin cities of Islamabad-Rawalpindi considered as population for journalist data. On the basis of available practices and volume of the media business, it is assumed that about 1,200 journalists are currently attached with these media groups in all the cities of the country while about 250 journalists are based in these two cities. Karachi, Lahore, Hyderabad and Faisalabad being big cities have the bigger media houses with having great number of journalists. To get information on the issues of the study, two separate questionnaires were served to the working journalists and users of the news outlets. The first population was based on all types of journalists who were part of the mainstream media outlets of these eight groups; print, electronic, and online. The sample of the study was designed keeping in view the volume and audience share of the top eight media groups. From a population of 250 mainstream journalists, 100 senior journalists having more than five years' experience in these media groups based in twin cities Islamabad-Rawalpindi were chosen through convenient sampling method. The researchers collected representative sample of the journalists from all the understudied media groups proportionally as; 36 from Jang and Geo, 14 each from The Government and ARY, 12 journalists from Express, 8 from Sama, Nawa-e-Waqt, and Dunya got 6 each while 4 journalists selected from Dawn. The questionnaire got filled in face-to-face meetings to avoid any confusion on the questionnaire. The process of collection of data from journalists was based on one-month time from May $2^{\text {nd }} 2021$ to May $31^{\text {st }} 2021$.

Two hundred regular subscribers and users of these media groups who were living in IslamabadRawalpindi was the second sample. 100 each media users from Rawalpindi and Islamabad were selected and the got the questionnaire filled in face-to-face meetings. The target media consumers were divided into two sections: urban and rural. The time of collection of data was April 15 2021 to May $31^{\text {st }} 2021$. Both quantitative and qualitative methods were used to get the objectives of the study. Altogether, 11 questions were asked to the journalists to explore; i) editor and owner influence on content choices, ii) journalists independence in selecting issues and topics, iii) influence of business community, politicians, and advertisers on journalistic independence, iv) media's political and ideological affiliation, v) media's relations with the business community, vi) journalists association support in internal and external pressures, vii) importance of truth and objectivity in editorial line viii) content concentration, diversity in content etc. The questionnaire was designed on a 5-point Likert scale. 
For getting audience perspective, five questions were posed which were based on: i) diversity in contents, ii) influence of cross-media ownership, iii) public trust in media, and iv) most trusted medium. The data were cross-examined and correlated to find a relationship between cross-media controlled patterns and audiences' opinion on media diversity, levels of public trust in media, and most trusted media. This questionnaire was also prepared on 5-point Likert scale.

Table 5 suggests the reliability coefficients (alpha) turned into 0.843 for the journalists' sample which strongly meet the desirable degree of 0.7 or higher.

Table 5. Reliability of the sample

\begin{tabular}{lcc}
\hline & $\mathrm{N}$ & $\%$ \\
\hline Cases & 12 & 100.0 \\
Excluded & 0 & 0.0 \\
Total & 12 & 100.0 \\
\hline
\end{tabular}

\section{RESULTS/FINDINGS}

The results were extracted from the opinion of journalists and media users through two separate survey questionnaires. The results are given in Figure 1. Responding to the question that how do you rate public confidence in media as depicted in Figure 1, the majority (70\%) of the audience have shown low degree of confidence in media. Regarding the influence of cross-media ownership on content diversity, the majority of the audiences were of the view that cross-media ownership has a great influence on content diversity and journalistic independence as shown in Figure 1.

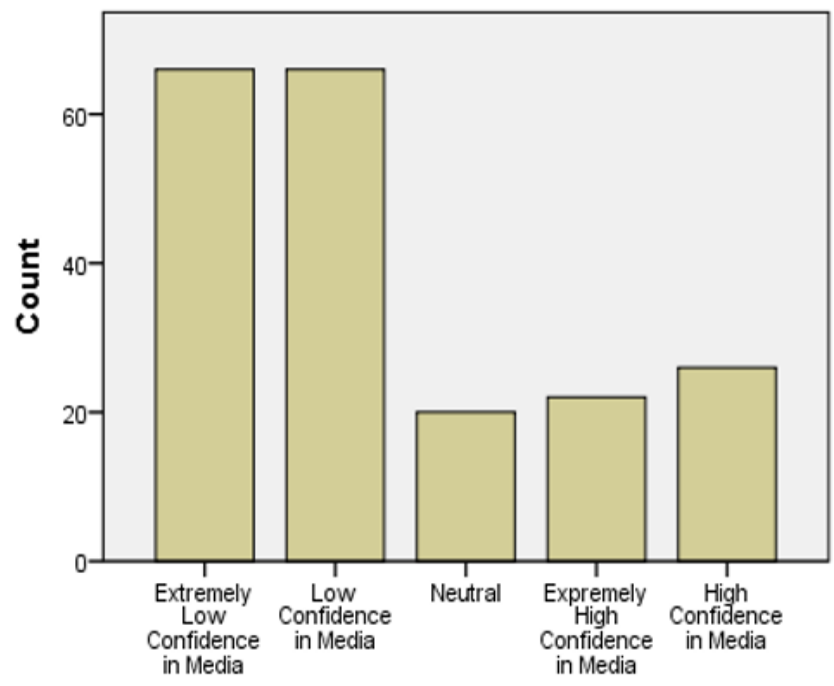

Figure 1. Public confidence in media

Figure 2 indicates majority (64\%) of the journalist viewed that influence is exerted by the owners on the overall journalistic independence in the opinion of journalists. Figure 2 also shows that the majority (70\%) of journalists see the direct influence of the media owners on editorial policies. The pressure and influence can be cross-examined through measuring cross-media ownership concentration trends in Pakistan that is $60 \%$ in terms of audience share among the top seven media groups. 


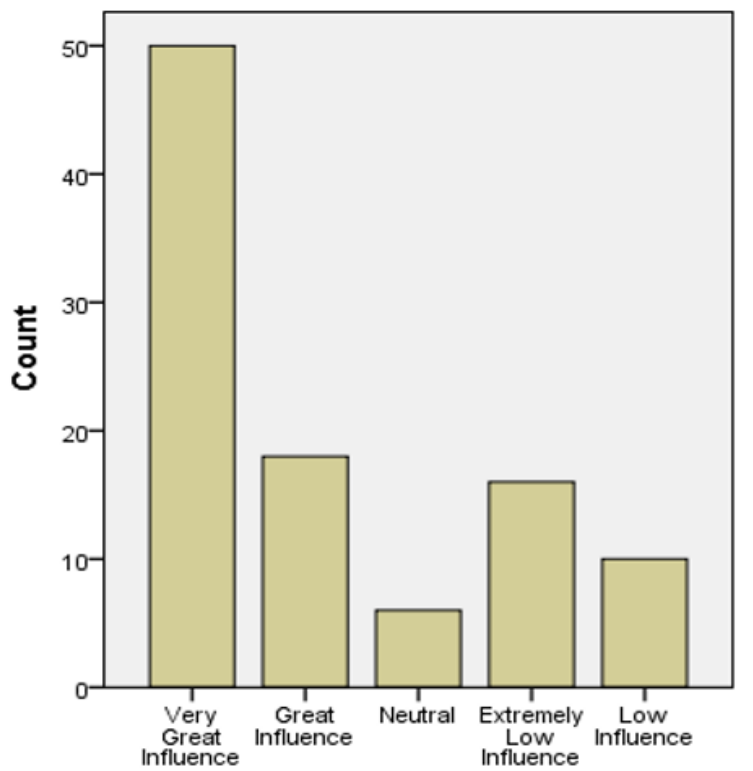

Figure 2. Influence of cross-media ownership on content diversity - Audience perception

Figure 3 shows that 54\% of journalists are agreed that the owner does define the editorial policy while $22 \%$ agreed that advertisers set the policy line for the media outlet. Editor and business community were placed at third.

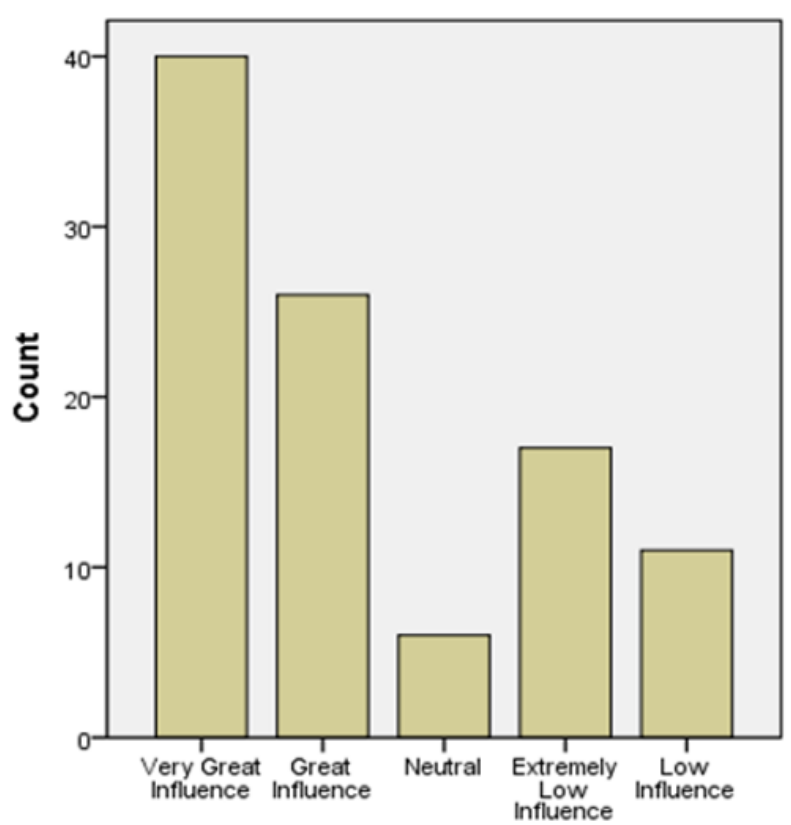

Figure 3. Influence on journalistic independence - Journalists' perception

As visible in Figure 4, the majority $75 \%$ of journalists say that media get influenced by political or religious groups. 


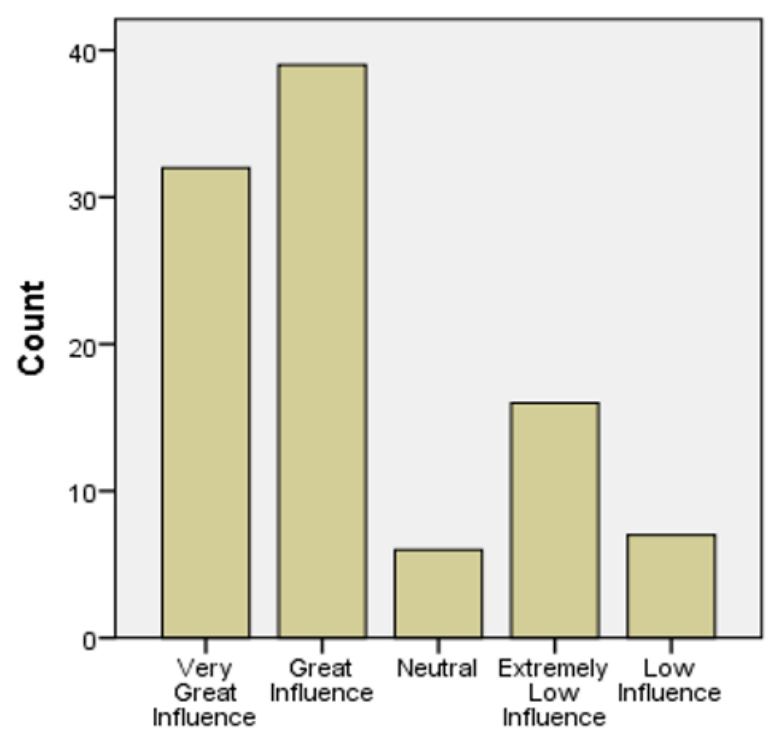

Figure 4. Owner's direct influence on editorial policies

As seen from Figure 5, 38\% of journalists say that media associations do not support them at the time of pressure on them while $35 \%$ observed that the associations do helpful to some extent.

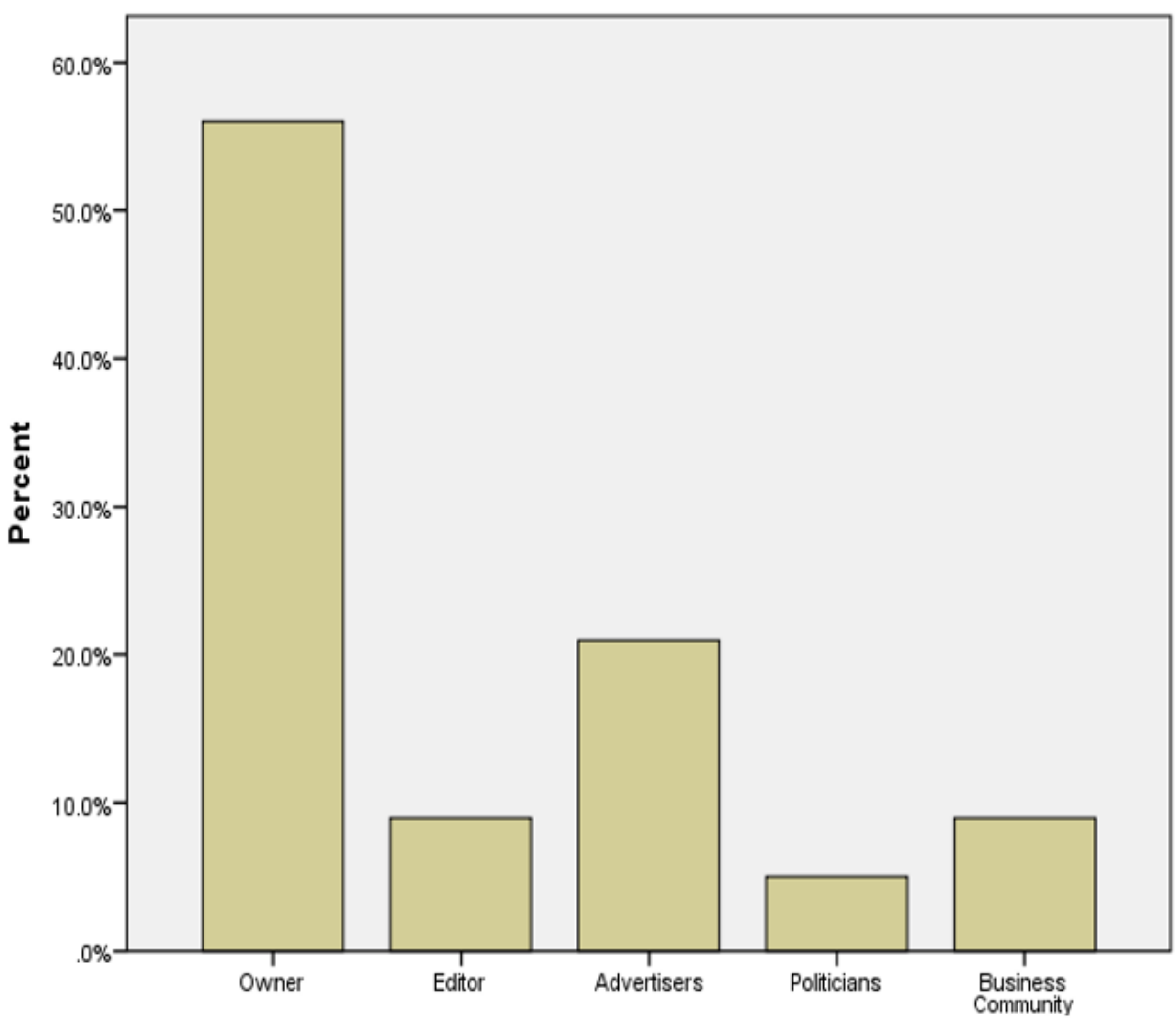

Figure 5. Who defines the editorial policy of your media outlet?

Table 6 shows positive uphill correlations of $>.52$ between public confidence and owners' influence on journalistic independence has been calculated. 
Table 6. Public confidence and owners influence on journalistic independence

\begin{tabular}{lllcc}
\hline \multicolumn{4}{c}{ Correlations } \\
\hline \multirow{2}{*}{$\begin{array}{l}\text { Spearman's } \\
\text { rho }\end{array}$} & $\begin{array}{l}\text { Public confidence in } \\
\text { media }\end{array}$ & $\begin{array}{c}\text { Correlation coefficient } \\
\text { Sig. (2-tailed) }\end{array}$ & 1.000 & $\begin{array}{c}\text { Influence on journalistic } \\
\text { independence }\end{array}$ \\
\cline { 2 - 5 } & $\mathrm{N}$ & Correlation coefficient & .50 & $.520^{* *}$ \\
& Influence on & media & .000 \\
& journalistic & Sig. (2-tailed) & $.520^{* *}$ & 100 \\
\hline & independence & $\mathrm{N}$ & .000 & 1.000 \\
\hline
\end{tabular}

**. Correlation is significant at the 0.01 level (2-tailed).

Table 7 shows an almost perfect correlation of >.92 between journalists' opinion on content concentration and audience opinion on content concentration has been found.

Table 7. Journalist opinion and audience opinion on content concentration

\begin{tabular}{|c|c|c|c|c|}
\hline \multicolumn{5}{|c|}{ Correlations } \\
\hline & & & $\begin{array}{l}\text { Journalists opinion on } \\
\text { content concentration }\end{array}$ & $\begin{array}{l}\text { Audiences opinion on } \\
\text { content concentration }\end{array}$ \\
\hline \multirow{6}{*}{$\begin{array}{l}\text { Spearman's } \\
\text { rho }\end{array}$} & \multirow{3}{*}{$\begin{array}{l}\text { Journalists' opinion on } \\
\text { content concentration }\end{array}$} & Correlation coefficient & 1.000 & $.920^{* *}$ \\
\hline & & Sig. (2-tailed) & & .000 \\
\hline & & $\mathrm{N}$ & 100 & 100 \\
\hline & \multirow{3}{*}{$\begin{array}{l}\text { Audiences' opinion on } \\
\text { content concentration }\end{array}$} & Correlation coefficient & $.920^{* *}$ & 1.000 \\
\hline & & Sig. (2-tailed) & .000 & \\
\hline & & $\mathrm{N}$ & 100 & 200 \\
\hline
\end{tabular}

**. Correlation is significant at the 0.01 level (2-tailed).

As indicates in Figure 6, the majority about $70 \%$ of audiences do experience homogeneity of the content. $23 \%$ of audiences observe it rarely. In Figure 6 , the level of most trusted medium is calculated, and audiences are considered TV as the most trusted medium with a $48 \%$ score while social media is remained at second place having a score of $26 \%$. The media users have placed print media as third most medium while radio and internet were least trusted.

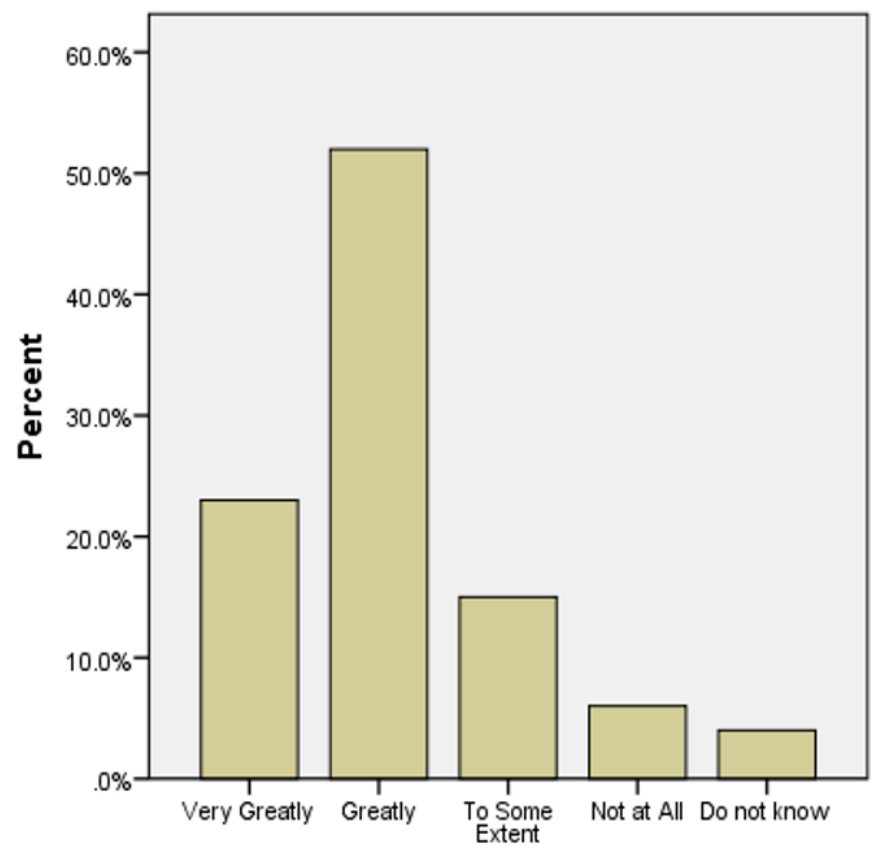

Figure 6 . Influence of political and religious groups on journalistic independence

As visible in Figure 7, about $61 \%$ of audience have the opinion that media do involve in partisanship on political, religious, ethnic, and ideological grounds. 


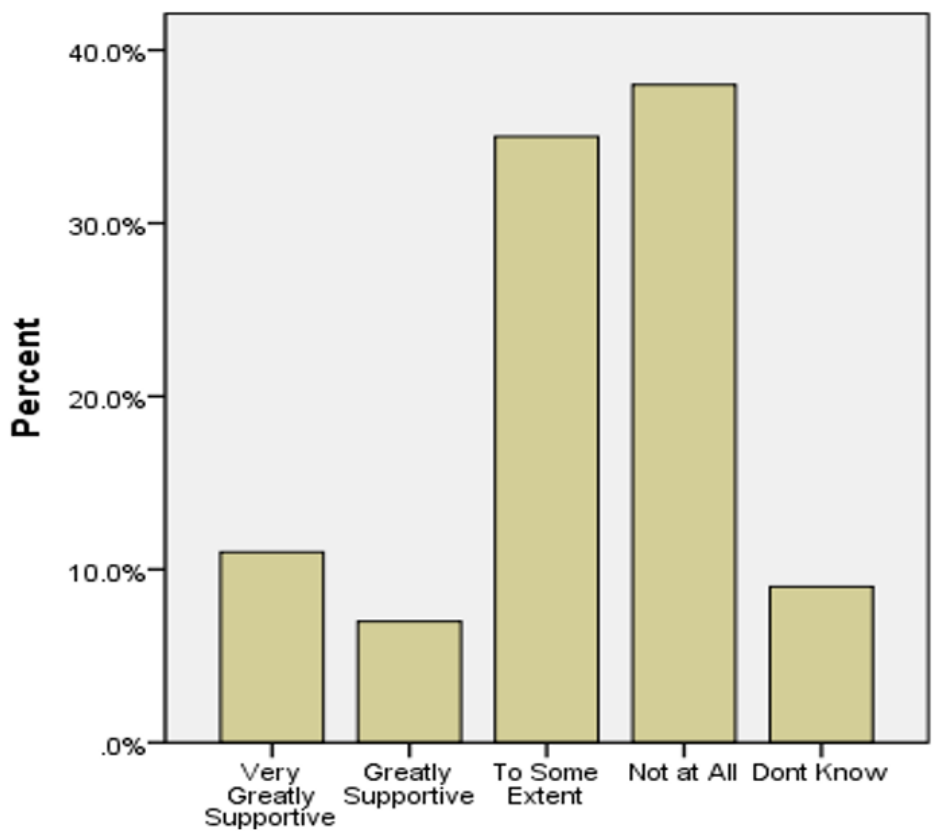

Figure 7. Journalists' association support in external or internal pressures on media workers

Figure 8 speaks that the majority $60 \%$ of the journalists do not feel free to compose their personal opinion on any issue. Only $22 \%$ went against it and observe freedom in their day-to-day professional assignments.

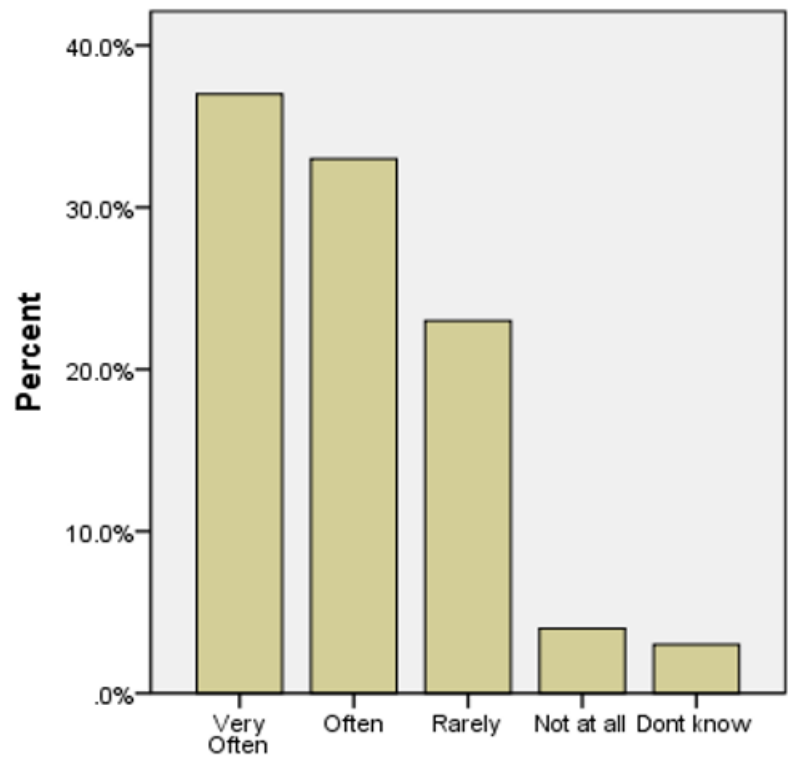

Figure 8. Homogeneity of the content 


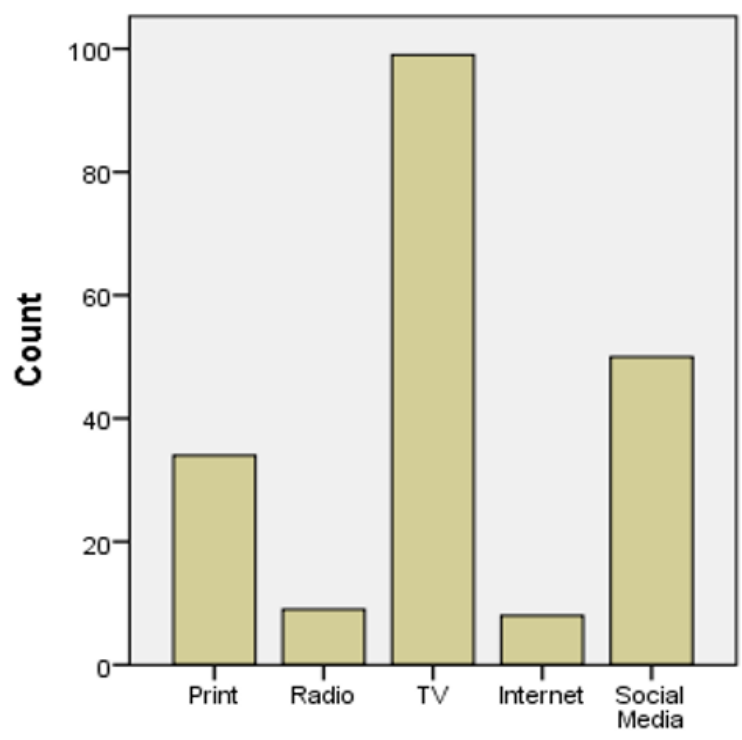

Figure 9. Which media platform you trust the most?

\section{DISCUSSION}

This research study has look at media concentration in print media, radio, television and social media in Pakistan. A significant uphill correlation $>.52$ is observed between public confidence in media and public perception about owners' influence on media content as depicted in Table 6. In the UK, Spain, North Macedonia, and Greece, the majority of citizens do not trust the media. In Finland, Albania, and the Netherlands, only $20 \%$ of the population or less do not trust the media (European Broadcasting Union, 2020). It might consider that owners' influence on journalistic independence directly as well as indirectly affects the overall confidence level of the audiences in media. It is evident from Table 1 above that cross-media ownership concentration is $69 \%$ which comes under the high-risk indicator of media concentration parameters. These eight media groups having $69 \%$ of cross-media productions in the country (Table 1). Reporters without Borders (2013) says that "a media sector calls as medium concentrated if within one country top 8 owners have an audience share between $50 \%$ and 69\%".

Jang Group is leading with a $25 \%$ television audience share among the top four media groups as listed in Table 2. ARY News and state-owned PTV News have almost equal shares (12\%) of the television audience. James (2020) observed that citizens' lack of digital fluency and their apathy produce an ill-informed and/or dispassionate public, weakening democracy and the fabric of society. The effects of cross-media ownership can be calculated in terms of audience shares in different media sectors like TV, print, and online. Therefore, the results of the study support to third hypothesis, "there will be a relationship between public confidence in media and public perception about owners' influence.

Table 3 shows that the Pakistani print media landscape is highly concentrated as the top 4 media groups have a $62.49 \%$ readership share. The criteria to measure the print media concentration is if a country has top 4 owners having an audience share above $50 \%$ (Reporters without Borders, 2019). In this case, Pakistani print platforms are highly concentrated which has effects on journalistic independence and control over information gathering and dissemination, therefore, our results, generally, support to the hypotheses first and second which talk about overall independence in editorial policies and of journalistic freedom (Figure 2). The results verify the ingredients of the propaganda model that says "it traces the routes by which money and power are able to filter out the news fit to print, marginalize dissent, and allow the government and dominant private interests to get their messages across to the public." (Herman \& Chomsky, 1988).

"Labour politicians have had over the last 20 years with News Corporation, News International and all the rest of it." (Reuters, 2012). Instead of concentration, diversity in news media leads to the diversification in an opinion that directs and facilitates the social system for democratic transition and change. In another way, like single media entity as cross-media or media concentration, can harm the diversity in the sources of news and opinion. Homogenized and constrained media have control to provide information in a less diversified 
way and this practice gives more power to media owners. According to the results, $2^{\text {nd }}$ and $6^{\text {th }}$ hypotheses "cross-media ownership will effect on the diversity of news content", and "media concentration will lead to content concentration are settled at supporting state. Gul et al. (2017) argue "that the growing concentration of ownership of capital in the media sector is quite evident in becoming a challenge for society and politics of the country." It is evident from Table 2 that the Pakistani TV market is highly concentrated as 4 media groups have a $55 \%$ share of the audience in TV medium platforms. In other way it falls under the hegemonic structures as defined in Herman and Chomskly's (1988) propaganda model.

The score is in the high-risk indicator for media-state relationships (MoMP, 2019). This favouritism can be seen towards some particular media groups in terms of public advertisement and on the other hand, the media they are critics to the government can be penalized in several ways. Responding to the question that how do you rate public confidence in media as depicted in Figure 1, the majority $70 \%$ of the audience have shown low confidence in media. Regarding the influence of cross-media ownership on content diversity, the majority $64 \%$ of audiences were of the view that cross-media ownership harms content diversity and journalistic independence as shown in Figure 1. In this way, results have supported the third hypothesis. Figure 2 shows the direct influence of the media owners on editorial policies. Although $28 \%$ of the journalists viewed the low influence of the owner on their journalistic freedom; however, in a broader scenario, the coverage or deletion of the topic or issue considers as the sole domain of the owners. The influence from the owners is creating underrepresentation or overrepresentation of few groups, parties, and classes in the society. Thus the first hypothesis of the research study that "media concentration will affect the editorial independence (choice of topics and independent opinion) of the journalists" is approved. Anonymous survey appears that about $22 \%$ of the inquired journalists have the opinion that advertisers do decide the editorial policy. The results further explored $54 \%$ of the journalists opined that media owners are the ultimate decisionmakers on the editorial line (a certain editorial tilt on policy issues). Editors and the business community remain in third place with a 9\% score each on the question "who decides the editorial policy of your media outlet? (Figure 3). Herman and Chomsky (1988) talk about the utility and usefulness of their model and they say that "It should be useful where it has a dominantly private ownership economy, a mainly commercial media depending heavily on advertising, and substantial inequality." The results of the study are supported the second hypothesis, "cross-media ownership will affect journalistic independence".

Talking about the pressures on the media by political and religious groups; the majority $75 \%$ of journalists opined that their media outlets have some specific political or religious pressures (Figure 4). Responding to the question; to what extent journalists' associations are supportive in external or internal pressures on media workers? $38 \%$ of journalists say that media associations do not support them at the time of pressures on them while 35\% observed that the associations do help to some extent (Figure 5). The continuous internal and external pressures on journalists do hurt the overall independent and fair media business and, in this situation media associations are very important. It means the environment of the country is not media friendly as the media associations are not so effective, loud and powerful keeping in view the hegemonic structures of the media system.

Regarding the inquiry of the homogeneous or similar content generation on the cross-media platforms, the majority $70 \%$ of the audience experience homogeneity in the content of their media outlets while only $23 \%$ observe it happens rarely (Figure 6). The results support to our $3^{\text {rd }}$ hypothesis which says "cross-media ownership will affect the diversity of news content." Figure 6 also indicates the levels of most and least trusted media platforms. The majority $48 \%$ went for Television as the most trusted medium while the internet and radio have been declared as the least trusted news platforms. Hypothesis posed that "TV will be the most trusted platform" is approved. Against the proposed hypothesis 5 that "social media will be the least media platform", social media has come up as the second most trusted medium. Since traditional media especially print media is in sharp decline, social media has given a tough time to television media. Therefore, fifth hypothesis is disapproved.

There is a perfect correlation $>.92$ (Table 6) observed between journalists' and audience opinion on content concentration which shows the homogeneity of the content. Since the diversity of news content is considered a lifeline for democratic culture and media development, it is possible through pluralism in media. In response to the question posed that "do you feel free to voice and write your personal opinion, even if it differs from the official line of the paper? $60 \%$ of the sample view that they do not feel much freedom to 
express a personal opinion if it is contrary to the official line of the media outlet and they remain under pressure by the owner not to write about certain topics. Only 22\% went for the option 'Yes' (Figure 8). The outcome of this question is also supported to the seventh hypothesis, "Journalists will not be free to voice their opinion if differs from the official line". Since the second decade of this century, print media is at decline in the country, therefore, the readership and journalists in print media outlets are being decreased sharply.

\section{CONCLUSIONS}

Pakistan, has experienced three decades of hybrid systems of government, three decades of dictatorship, and a decade of emerging but fragile democracy in its 75 years history. Through the time, it is lacking in having consistent, experienced and well-trained journalistic community. The absence of a proper media-business model in the country, the development and growth of the media sector in this part of the world has remained under multiple challenges and problems. The media is having a traditional economic model based on advertisements quantity and subsidies in media sector from the government. Further, unstable and fragile political system and interventions of powerful elite media ownership have been curbing journalistic independence, objectivity and transparency in the media systems.

The objective of this study was to highlight the obligations of the media and media owners in overall processes and penetration of the media concentration in Pakistan. Further, the study was designed to get the opinion of the public regarding their trust in media and opinion about content diversification. Since, in recent years in the country, the phenomenon 'media concentration', in all the four dimensions; chain ownership, cross-media ownership, conglomerate ownership, and vertical integration have been flourished, preferred and considered as safe as far as the business of media is concerned. The most expanded type of media in Pakistan are cross-media and chain ownership. Jang and Geo group has been at top in terms of cross and chain ownership. ARY group is enjoying cross-media ownership, however, the group has non-media businesses as well. Express group is also a non-media business group and its major financial stakes with other businesses. Dawn, Nawa-i-Waqt, Sama, and Jang and Geo are purely considered as media businesses. In this sense, major part of Pakistani mainstream media landscape is based on media business.

According to our findings and review of previous literature, these consolidation patterns of media ownership in recent decades in Pakistan have reduced diversity in news and opinion in all formats of media platforms, print, electronic and digital. The media users think that homogeneous content is not helping in making a logical decisions and reasoning based objective opinion that normally comes from homogenous sources. The users of media, in other words, are victims of such media houses in terms of receiving similar news stuff. The results of the study state that journalists have to face numerous types of influences and pressures from owners, advertisers, business community, political, ethnic and religious groups for what to be covered or what not to be. The different narratives or partisanship of the media can be a product of political, religious, ideological or communal beliefs which could ultimately be a source of commercial gains. Majority of the journalists believe that the cross-media ownerships concentration does pave to sell partisanship through concentrated audience share. Few groups are running a major chunk of mainstream media platforms in Pakistan and it causes less diversification in media ownership and content generation. This perception of the journalists reflects the argument of Herman and Chomsky (1988) that content generation and dissemination is the end product of government and corporate propaganda to safeguard their vested interests through manufacturing consent and commercial gains respectively. MoMP's (2019) observations and the outcome of this study show that Pakistani media is in the high risks slab as far as media pluralism is concerned. This is observed that media owners influence is not different in nature but different in the strategy. Since Pakistani media has not a sustainable economic model, they have to rely on the traditional model of advertisements; private or public. The journalists get influenced from internal and external actors and structural extensions. However, the results show all these pressures and influences are verified as the product of expected commercial gains. The study further concludes that Television media is considered as the most trusted media platform while social media came up as the second most trusted media platform. Since, the country's $65 \%$ population is based on youth, the trend of using social media is increasing and trust on this platform has increased during the last decade. The study shows that Pakistani cross-media ownership pattern is curtailing the independence of the media workers and overall independent environment of editorial policies. 
Author contributions: All authors were involved in concept, design, collection of data, interpretation, writing, and critically revising the article. All authors approve final version of the article.

Funding: The authors received no financial support for the research and/or authorship of this article.

Declaration of interest: Authors declare no competing interest.

Data availability: Data generated or analysed during this study are available from the authors on request.

\section{REFERENCES}

Alger, D. (1998). Megamedia: How giant corporations dominate mass media, distort competition, and endanger democracy. Rowman \& Littlefield Publishers.

Arab News. (2019). Journalism in Pakistan 2019: Layoffs, censorship, violence. https://www.arabnews.pk/node/1606556/pakistan

Baker, C. E. (2007). Media concentration and democracy: Why ownership matters. Cambridge University Press. https://doi.org/10.1017/CBO9780511810992

Chomsky, N. (2002). Media control: The spectacular achievements of propaganda. Seven Stories Press.

Chomsky, N. (2004). Hegemony or survival: America's quest for global dominance. Penguin.

CIMA. (2019). Declining public support for media freedom in Africa: What does it mean for democratic values on the continent? https://www.cima.ned.org/blog/declining-public-support-for-media-freedom-in-africawhat-does-it-mean-for-democratic-values-on-the-continent/

Corcoran, M. (2016). Twenty years of media consolidation has not been good for our democracy. Bill Moyers. https://billmoyers.com/story/twenty-years-of-media-consolidation-has-not-been-good-for-ourdemocracy/

Council of Europe. (2009). Methodology for monitoring media concentration and media content diversity. https://rm.coe.int/CoERMPublicCommonSearchServices/DisplayDCTMContent?documentld=09000016 $80483 \mathrm{~b} 18$

Doyle, G. (2002). Media ownership: The economics and politics of convergence and concentration in the UK and European media. SAGE.

European Broadcasting Union. (2017). Trust in media. https://medienorge.uib.no/files/Eksterne_pub/EBU-MISTrust_in_Media_2020.pdf

Fischer, C. (2019). What is meant by 'trust' in news media? In K. Otto \& A. Köhler (Eds.), Trust in media and journalism, (pp.19-38). Springer. https://doi.org/10.1007/978-3-658-20765-6_2

Fùrnemont, J.-F., \& Trpevska, S. (2020). Pluralism of media ownership in the media environment: $A$ study for the agency for audio and audiovisual media services. https://rm.coe.int/hf37-study-media-ownershipeng/16809f0272

Gallup. (2020). Confidence in institutions. https://news.gallup.com/poll/1597/confidence-institutions.aspx

Gans, H. J. (1979). Deciding what's news: A study of CBS evening news, NBC nightly news, newsweek, and time. Medill Visions of the American Press.

Gul, M., Obaid, Z., \& Ali, S. (2017). Liberalization of media in Pakistan: A challenge to democracy. The Journal of Humanities and Social Sciences, 25(1).

Harkinson, J. (2014). Ever wonder why your local TV news stations run the same damn stories?. Mother Jones, 4(4). https://www.motherjones.com/media/2014/04/fcc-pew-local-tv-news-consolidation/

Herman, E. S., \& Chomsky, N. (2002). Manufacturing consent: The political economy of the mass media. Pantheon Books.

Herman, E., \& Chomsky, N. (1988). A propaganda model. https://chomsky.info/consent01/

Karachi Union of Journalists. (2019). https://kuj.net.pk/

Liebling, A. J., Mencken, H. L., Woelfel, N., \& Calwell, A. (2006). Freedom of the press is guaranteed only to those who own one. https://quoteinvestigator.com/2015/05/21/free-press/

Light, J. (2017). How media consolidation threatens democracy: 857 channels (and nothing on). https://billmoyers.com/story/media-consolidation-should-anyone-care/

Media Landscape. (2019). Pakistan. https://medialandscapes.org/country/pakistan/media/print

Mezzera, M., \& Sial, S. (2010). Media and Governance in Pakistan: A controversial yet essential relationship. Initiative for Peace Building. https://gsdrc.org/document-library/media-and-governance-in-pakistan-acontroversial-yet-essential-relationship/ 
MoMP. (2019). Media ownership Monitor Pakistan. https://pakistan.mom-rsf.org/en/findings/findings/

Newman, N., Fletcher, R., Schulz, A., Andi, S. \& Nielsen, R. K. (2020). Reuters institute digital news report. https://reutersinstitute.politics.ox.ac.uk/sites/default/files/2020-06/DNR_2020_FINAL.pdf

O'Rourke IV, J. S. (2020). Exploiting digital illiteracy: Citizens' lack of digital fluency and their apathy produce an illinformed and/or dispassionate public, weakening democracy and the fabric of society. https://www.pewresearch.org/internet/2020/02/21/concerns-about-democracy-in-the-digital-age/

Papendrea, F., \& Tiffen, R. (2016). Media ownership and concentration in Australia. In E. M. Noam (Ed.), Who owns the world's media? (pp.703-739). Oxford University Press. https://doi.org/10.1093/acprof:oso/9780199987238.003.0023

Parenti, M. (2016). Methods of media manipulation. https://media-alliance.org/2016/05/methods-of-mediamanipulation-by-michael-parenti/

Paveli, D. (2010). Berlusconi's chilling effect on Italian media. https://www.opensocietyfoundations.org/voices/berlusconi-s-chilling-effect-italian-media

PEMRA. (2007). PEMRA Amendment Act, 2007 (Act No. II of 2007). http://pid.gov.pk/uploads/media_laws/Ordinance_2002.pdf

Rasul, A. \& Proffitt, J. M. (2013). Diversity or homogeny: Concentration of ownership and media diversity in Pakistan. Asian Journal of Communication, 23(6), 590-604. https://doi.org/10.1080/01292986.2013.805797

Reporter without Borders. (2019). Too much media in too few hands. https://pakistan.momrsf.org/en/findings/concentration

Reporters without Borders. (2020). Tougher politics, more press freedom violations. https://rsf.org/en/rsf_search?key=bangladesh

Reuters (2012). The twist in Murdoch saga strains Britain's coalition. https://www.reuters.com/article/usbritain-politics-idUSBRE85COF720120613

Riaz, A., \& Rahman, M. S. (2021). Who owns the media in Bangladesh? https://bdmediaowners.com/wpcontent/uploads/2021/01/Full-Report_Who-Owns-the-Media-in-Bangladesh.pdf

Shoemaker, P. J. (1987). Mass communication by the book: A review of 31 texts. Journal of Communication, 37(3), 109-131. https://doi.org/10.1111/j.1460-2466.1987.tb00998.x

Shoemaker, P. J., \& Reese, S. D. (1996). Mediating the message: Theories of influence on mass media content. Longman.

Sjøvaag, H., \& Ohlsson, J. (2019). Media ownership and journalism. Oxford University Press. https://doi.org/10.1093/acrefore/9780190228613.013.839

Strömbäck, J., \& Karlsson, M. (2011). Who's got the power? Journalists' perceptions of changing influences over the news. Journalism Practice, 5(6), 643-656. https://doi.org/10.1080/17512786.2011.592348

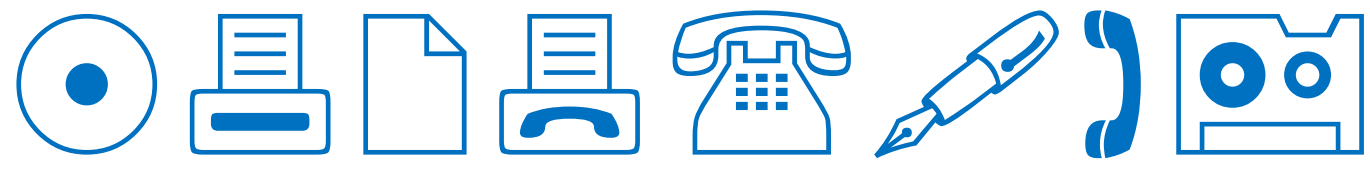

